\title{
Ethyl (E)-4-(oxo-[1,3]thiazinan-2-ylidene)ethanoate.
}

\author{
Marija Baranac ${ }^{\mathrm{a}}$, Rade Marković ${ }^{\mathrm{a}}$ and Peter J. Steel ${ }^{\mathrm{b}}$

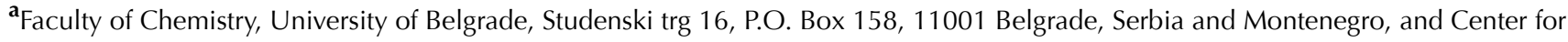 \\ Chemistry ICTM, P.O. Box 815, 11000 Belgrade, Serbia and Montenegro, and ${ }^{\mathbf{b}}$ Department of Chemistry, University of Canterbury, \\ Christchurch, New Zealand
}

Correspondence email: peter.steel@canterbury.ac.nz

\begin{abstract}
The structure and stereochemistry of the title compound have been determined at $163 \mathrm{~K}$. The two independent molecules each possess an extended planar conformation with an intramolecular $\mathrm{NH}^{*} \mathrm{O}$ hydrogen bond.
\end{abstract}

\section{Comment}

The title compound (1), with E-configured exocyclic double bond, was obtained in low yield from the heterocyclization of ethyl cyanoacetate with ethyl 3-mercaptopropanoate in ethanol (Marković et al., 2003).

[Structure of (1) here]

This reaction served as a model to confirm the regiocontrolled synthesis of $(Z)$-5-substituted-4-oxothiazolidine derivatives (4) in good yields (60-80\%), occurring via the base-catalyzed heterocyclization of $\beta$-oxonitriles (2) with diethyl mercaptosuccinate. These reactions were found to take place without detectable traces of the competing six-membered 6-substituted 4-oxo-1,3-thiazinane derivatives (5), which could be formed from the key intermediates (3), which possess two electrophilic centres. However, the intermediates (3) readily undergo intramolecular cyclization only by path a, affording under kinetic control the stereodefined 4-oxothiazolidine derivatives (4) (Marković \& Baranac, 1998; Marković et al., 2001). Therefore, (i) the sluggish heterocyclization reaction giving rise to the title compound under relatively drastic reaction conditions, and (ii) the exclusive formation of the five-membered heterocycles (4) without traces of (5) (Scheme, path a), rely critically on the lower tendency towards cyclization of the common intermediates (3) to give the six-membered heterocycles (5) (path b).

[Scheme here]

Compound (1) crystallizes in the monoclinic space group P2/n, with two independent molecules in the asymmetric unit, a perspective view of one of which is shown in Figure 1. This unambiguously confirms the structure previously proposed for this compound (Marković et al., 2003) and for the first time determines the stereochemistry of the exocyclic double bond. Interestingly, this has the E-configuration, in contrast to the analogous five-membered thiazolidine compounds which have the Z-configuration, despite being formed under very similar experimental conditions (Marković et al., 2003). The two independent molecules differ only in small torsional angle differences within the molecules. The molecules themselves are surprisingly planar, with the side chain extending out in the same plane as the thiazine ring. A contributing reason for this 


\section{Acta C preprint}

is the existence of an intramolecular hydrogen bond between the NH group and the carbonyl oxygen of the side chain, as defined by the following parameters: $\mathrm{H}-\mathrm{O} 2.09$ (3) and 2.16 (3) $\AA, \mathrm{N}-\mathrm{O} 2.728$ (2) and 2.731 (2) $\AA, \mathrm{N}-\mathrm{H}-\mathrm{O} 131$ (2) and 129 (2) ${ }^{\circ}$, for the two independent molecules, respectively. This stablilizing interaction may acount for the observed formation of the E-stereoisomer. A search of the Cambridge Structural Database (Allen, 2002) revealed that this is the first reported structure of a 2-alkylidene[1,3]thiazin-4-one.

[Fig.1 here]

\section{Experimental}

Compound (1) was synthesized as a pale yellow solid by the heterocyclization of ethyl cyanoacetate with ethyl 3-mercaptopropanoate; m.p. $66-67^{\circ} \mathrm{C}$. Single crystals suitable for X-ray analysis were obtained by slow evaporation of a dilute ethanol solution of the title compound. Spectroscopic data: IR (KBr): $v_{\max } 3195,3073,1689,1656,1583,1445,1366,1230,1188$, 1155, $793 \mathrm{~cm}^{-1}$; ${ }^{1} \mathrm{H}$ NMR (DMSO-d 6 ): $\delta 1.19\left(3 \mathrm{H}, \mathrm{t}, \mathrm{J}=7.1 \mathrm{~Hz}, \mathrm{CH}_{3}\right), 2.85\left(2 \mathrm{H}, \mathrm{m}, \mathrm{CH}_{2}\right), 3.21\left(2 \mathrm{H}, \mathrm{m}, \mathrm{CH}_{2}\right), 4.10(2 \mathrm{H}, \mathrm{q}, \mathrm{J}$ $\left.=7.1 \mathrm{~Hz}, \mathrm{CH}_{2} \mathrm{O}\right), 5.12(1 \mathrm{H}, \mathrm{s},=\mathrm{CH}), 11.11(1 \mathrm{H}, \mathrm{s}, \mathrm{NH}) ;{ }^{13} \mathrm{C} \mathrm{NMR}\left(\mathrm{DMSO}_{-} \mathrm{d}_{6}\right): \delta 14.4\left(\mathrm{CH}_{3}\right), 23.0\left(\mathrm{CH}_{2} \mathrm{~S}\right), 33.2\left(\mathrm{CH}_{2} \mathrm{CO}\right)$, $59.9\left(\mathrm{CH}_{2} \mathrm{O}\right), 90.1(=\mathrm{CH}), 154.5(=\mathrm{CSN}), 167.4$ and $168.1(2 x \mathrm{CO})$.; $\mathrm{MS}(\mathrm{EI}): \mathrm{m} / z$ (rel. intensity): $201(62)\left(M^{+}\right), 173(10)$, 156 (33), 129 (75), 55 (100); UV (DMSO): $\lambda_{\max }$ (ع) $298.4 \mathrm{~nm}\left(17900 M^{-1} . \mathrm{cm}^{-1}\right)$; Anal. Calcd. for $\mathrm{C}_{8} \mathrm{H}_{11} \mathrm{NO}_{3} \mathrm{~S}: \mathrm{C}, 47.75$; H, 5.51; N, 6.96; S, 15.93; Found: C, 48.06; H, 5.63; N, 6.92; S, 15.88\%.

\section{Refinement}

Crystal decay was monitored by the measurement of duplicate reflections. The NH hydrogen was located from a difference Fourier and its position refined. $\mathrm{CH}$ hydrogen were placed in calculated positions and refined as riding, with $U_{\text {iso }}=1.2 U_{\text {eq }}$ of the attached carbon.

\section{Computing details}

Data collection: Bruker SMART; cell refinement: Bruker SMART; data reduction: Bruker SAINT; program(s) used to solve structure: SHELXS97 (Sheldrick, 1990); program(s) used to refine structure: SHELXL97 (Sheldrick, 1997); molecular graphics: Bruker SHELXTL; software used to prepare material for publication: Bruker SHELXTL.

\section{Figures}

Figure 1. Perspective view of (1).

\section{Ethyl $(E)-4-($ oxo-[1,3]thiazinan-2-ylidene)ethanoate}

\begin{tabular}{|c|c|}
\hline $\mathrm{C}_{8} \mathrm{H}_{11} \mathrm{NO}_{3} \mathrm{~S}$ & $V=1877.84(19) \AA^{3}$ \\
\hline$M_{r}=201.24$ & $Z=8$ \\
\hline Monoclinic, $P 2 / n$ & Mo $K \alpha$ \\
\hline$a=14.0313(8) \AA$ & $\mu=0.32 \mathrm{~mm}^{-1}$ \\
\hline$b=9.1124(5) \AA$ & $T=163(2) \mathrm{K}$ \\
\hline
\end{tabular}


$c=15.0553(9) \AA$

$\beta=102.7030(10)^{\circ}$

\section{Data collection}

CCD area detector diffractometer

Absorption correction: multi-scan

SADABS (Sheldrick, 2002)

$T_{\min }=0.817, T_{\max }=0.984$

21284 measured reflections

Refinement

$R\left[F^{2}>2 \sigma\left(F^{2}\right)\right]=0.035$

$w R\left(F^{2}\right)=0.099$

$S=1.04$

3298 reflections
$0.66 \times 0.41 \times 0.05 \mathrm{~mm}$

\author{
3298 independent reflections \\ 2573 reflections with $I>2 \sigma(I)$ \\ $R_{\text {int }}=0.020$
}

\section{References}

Allen, F. H. (2002). Acta Cryst. B58, 380-388.

Bruker (1997). SMART, SAINT and SADABS. Area Detector Control and Integration Software. Siemens Analytical X-ray Instruments Inc., Madison, Wisconsin, USA.

Marković, R. \& Baranac, M. (1998). Heterocycles, 48, 893-903.

Marković, R., Baranac, M., Džambaski, Z., Stojanović, M. \& Steel, P. J. (2003). Tetrahedron, 59, 7803-7810.

Marković, R., Džambaski, Z. \& Baranac, M. (2001). Tetrahedron, 57, 5833-5841.

Sheldrick, G. M. (1990). Acta Cryst. A46, 467-473.

Sheldrick, G. M. (2002). SADABS. Version 2.03. University of Göttingen, Germany.

Sheldrick, G. M. (1997). SHELXL97. University of Göttingen, Germany. 